\title{
Cultura popular e educação popular: expressões da proposta freireana para um sistema de educação
}

\section{Popular culture and popular education: an expression of Freire's proposal for a kind of education system}

\author{
Carlos Rodrigues Brandão ${ }^{1}$ \\ Maurício Cesar Vitória Fagundes ${ }^{2}$
}

\begin{abstract}
RESUMO
Este artigo discute a proposta de cultura e educação popular, desenvolvida a partir dos anos 1960, por Paulo Freire, como possibilidade de articular e fundamentar sua proposta e/ou sistema de educação, contemplando da alfabetização à universidade. A proposta reúne elementos com forte suficiência para pensar a educação para além da concepção dita tradicional, em que a "informação cultural" em suas múltiplas expressões e a educação eram, ou ainda são, utilizadas como recursos pedagógicos para transferir a setores populares conhecimentos eruditos, carregados da lógica dominante. Os movimentos emergentes dos anos 1960, em que a cultura e a educação são rediscutidas em diálogo com a cultura popular, sonhavam tornarem-se meios para efetuar uma comunicação biunívoca, de efeito conscientizador. Para tal, tomam como referência os valores da cultura de grupos e comunidades populares como elementos próprios de reflexão coletiva sobre as condições de vida e o significado dos símbolos do povo; seguidos da reflexão coletiva que consubstanciasse o pensamento do povo de um sentido humano e crítico, que os movimentos de cultura popular reconheciam terem sido perdidos, ao traduzir-se em termos de "cultura de massas". Assim, importa empreender a recuperação dos valores do povo como aporte do novo modo
\end{abstract}

\section{DOI: $10.1590 / 0104-4060.47204$}

1 Universidade Federal de Uberlândia. Uberlândia, Minas Gerais, Brasil. Av. João Naves de Ávila, nº 2.121, Santa Mônica. CEP: 38.408-100.E-mail: carlosdecaldas@gmail.com

2 Universidade Federal do Paraná. Setor Litoral. Programa de Pós-Graduação em Educação. Matinhos, Paraná, Brasil. Rua Jaguariaiva, nº 512. CEP: 83.260-000. E-mail: mauriciovitoriafagundes@gmail.com 
de compreender o mundo, saber vivê-lo e transformá-lo. Nessa perspectiva, problematizamos possibilidades de transição da dita concepção tradicional para uma educação transformadora ou humanizadora, que abarque da alfabetização à universidade popular.

Palavras-chave: educação popular; cultura popular; sistema freireano de educação.

\begin{abstract}
This work discusses proposals of popular culture and popular education. The education system developed by Paulo Freire in 1960 can be applied from primary education to college. These proposals gather elements to think beyond the traditional education methods. In these methods, pieces of "cultural information" and education in their multiple expressions are used as pedagogical tools whose main purpose is the dissemination of dominant knowledge among a larger population. The social movements of the sixties, a time during which culture and education were rediscovered in a dialogue with popular culture, dreamt about becoming ways of performing a biunivocal communication of awareness effect. Then, they take values of groups' cultures and popular communities' values as adequate elements for collective reflection on living conditions and meanings of popular symbols; followed by a collective reflection that substantiated popular thoughts of human and critical sense, which popular cultural movements recognized as lost concepts that were thrown away when they were translated into "mass culture". Therefore, it should bring a renewed sense of how to interpret, live and transform the world. Thus, we discuss current possibilities of transforming traditional education into a new humanizing perspective that would encompass all levels of education, from primary schools to universities.
\end{abstract}

Keywords: popular education; popular culture; Freire's educational system.

\title{
A cultura, a educação popular e suas circunstâncias
}

A discussão sobre cultura e educação popular, em termos de tempos históricos, assenta-se no movimento pós-Segunda Guerra Mundial. O período foi mundialmente caracterizado como Guerra Fria e, em termos de Brasil, como período da redemocratização. No Brasil, vivia-se política, econômica e culturalmente o tensionamento estabelecido pela proposta capitalista, representada 
pelos Estados Unidos e Europa, manifestada por meio do modelo desenvolvimentista e, de outra banda, a proposta socialista, representada pela então União Soviética, China e Cuba.

Em se tratando do continente americano, no final da década de 1950 e nos anos iniciais da década de 1960, a Revolução Cubana acirrava os efeitos da Guerra Fria. Esse movimento de possibilidade de ruptura animava propostas de transformação da ordem social, consideradas injustas e inaceitáveis. De outro lado, os defensores da ordem estabelecida pelo grande capital resistiam a essas mudanças, porém percebiam que as precárias condições de vida das pessoas do Nordeste possuíam elementos para, quem sabe, transformar-se em uma segunda Cuba.

Nesse cenário, a Igreja Católica, por meio da Conferência Nacional dos Bispos do Brasil (CNBB), em março de 1961, criou o Movimento de Educação de Base (MEB), com o apoio do governo federal. O MEB tinha como preocupação inicial o desenvolvimento de um processo educativo, por meio de escolas radiofônicas, atingindo as zonas rurais das áreas subdesenvolvidas das regiões Norte, Nordeste e Centro-Oeste. As escolas radiofônicas, segundo Fávero (2006), já haviam sido utilizadas no ano de 1950 em uma experiência de alfabetização de adultos em Valença, no Rio de Janeiro, porém "[...] indica-se normalmente como sua matriz principal a experiência de Monsenhor Salcedo, em Sutatenza, que deu origem à Acción Cultural Popular (ACPO), na Colômbia”. (FÁVERO, 2006, p. 3).

Cabe destacar que a proposta de educação de base, originalmente, fazia parte do ideário da Organização das Nações Unidas para a Educação, a Ciência e a Cultura (UNESCO), em seus programas de educação para os povos subdesenvolvidos, e havia sido introduzida no Brasil a partir de 1947, pela Campanha Nacional de Alfabetização de Adultos e pela Campanha Nacional de Educação Rural (CNER), com atuação significativa até meados dos anos de 1950. (FÁVERO, 2006). Esse movimento da década de 1950 se caracteriza como uma transposição de experiências, que visavam atender a aceleração e a modernização do processo econômico brasileiro. As experiências se apresentavam como extensão rural, desenvolvimento de comunidades, educação de base e educação de adultos. (FÁVERO, 1983, p. 8).

A proposta de educação de base, estimulada pela UNESCO, desde 1947, fazia aproximações entre os altos índices de analfabetismo das populações adultas nas regiões consideradas como atrasadas e o baixo grau de desenvolvimento econômico, tomando como referência a ótica do capital. Logo, sob essa lente, o analfabetismo era um câncer que precisava ser eliminado, pois atrasava o desenvolvimento do Brasil. Nessa direção, o currículo proposto baseava-se em conhecimentos, como: ler, escrever e calcular, considerados como 
aprendizagens suficientes para o desenvolvimento do pensamento; trabalhos na agricultura, técnicas comerciais, trabalhos caseiros e edificação, para promover o desenvolvimento profissional e o progresso econômico; desenvolvimento de habilidades domésticas, para poder trabalhar com crianças, enfermos e preparação de alimentos; meios de higiene pessoal e coletiva, para o desenvolvimento moral e intelectual, entre outros.

Para Prado Junior (1966), o Brasil dos anos 1960 se encontrava em um momento pré-revolucionário,

[...] em face ou na iminência de um daqueles momentos acima assinala$\operatorname{dos}^{3}$ em que se impõem de pronto reformas e transformações capazes de reestruturarem a vida do país de maneira consentânea com suas necessidades mais gerais e profundas, e as aspirações da grande massa de sua população que, no estado atual, não são devidamente atendidas. (PRADO JUNIOR, 1966, p. 3).

Para além da proposta curricular e do entendimento de educação como preparadora de recursos humanos para a indústria e modernização da agropecuária, coexistia, também, a concepção de educação como formadora da consciência nacional e instrumentalizadora de profundas transformações político-sociais na sociedade brasileira, como possibilidade de emancipação humana.

Decorrente das discussões estabelecidas pelos países socialistas, como possibilidade de romper com o predomínio elitista da cultura, as expressões cultura popular, educação popular e educação de base eram colocadas como bem cultural de acesso a todo povo e, no contexto brasileiro, careciam do reconhecimento de suas positividades:

[...] procurava-se definir o papel da cultura na revolução brasileira. E as pessoas e os grupos que reescreveram essa expressão, no pródigo, embora conturbado Brasil dos anos 60 , tentaram praticar tudo que pensaram que ela queria e podia significar. Acreditavam sobretudo que por diferença ou por oposição, reinventavam ideias e propunham novas práticas. (FÁVERO, 1983, p. 7).

3 O "momento" a que se referia Prado Junior dizia respeito à "Revolução", a qual define como processo histórico assinalado por reformas e modificações econômicas, sociais e políticas sucessivas, que, concentradas em período histórico relativamente curto, vão dar em transformações estruturais da sociedade e, em especial, das relações econômicas e do equilíbrio recíproco das diferentes classes e categorias sociais. (PRADO JUNIOR, 1966, p. 2). 
Começava a organização de um projeto político educacional que, por meio da conscientização e da politização das classes populares, pudesse superar a dominação do capital e transformar, pelas mãos do povo, a ordem das relações de poder e da própria vida do país. Esse movimento não poderia prescindir do reconhecimento das positividades da cultura popular, entendida por Gullar (1983) como a tomada de consciência do povo acerca da realidade brasileira: "[...] é compreender que o problema do analfabetismo, como a deficiência de vagas nas Universidades, não está desligado da condição de miséria do camponês, nem da dominação imperialista sobre a economia do país". (GULLAR, 1983, p. 51).

A relação intrínseca entre dominantes e dominados, seja de outros países sobre o Brasil ou mesmo nas relações internas, manifesta-se no plano político-econômico e cultural. "A luta interna de libertação liga-se profundamente à cultura popular, que assume no primeiro momento o sentido de desalienação de nossa cultura, sobrepondo aos valores culturais estranhos, valores criados e elaborados aqui". (FÁVERO, 1983, p. 74). Reforça o autor que o sentido de cultura popular não é um meio político de preparação das massas para conquistar o poder, mas um profundo sentido dialético entre cultura popular e libertação humana.

Acerca da teoria da revolução brasileira, Prado Junior (1966, p. 15) defende que para ser algo “[...] efetivamente prático na condução dos fatos, será a interpretação da conjuntura presente e do processo histórico de que resulta. Processo esse que, na sua projeção futura dará cabal respostas às questões pendentes".

Nessa senda, a alfabetização de adultos de Paulo Freire e de seu grupo tinha como pressupostos o estabelecimento de uma relação dialética da educação com a cultura; a busca de um método ativo capaz de criticizar o homem através do debate de situações desafiadoras postas diante do grupo, que deveriam ser existenciais para o grupo. (FREIRE, 1983, p. 113). Decorrente desse processo, viria o movimento de construção de uma nova concepção de educação, cujo foco não seria mais instrumental, mas um método dialogal, ativo, participante, crítico e criticizador sobre sua vida, suas relações com o meio e sua percepção como sujeito ativo, tendo a cultura como resultado de seu trabalho.

\section{Paulo Freire e a cultura popular}

Paulo Freire, ao relatar sobre sua trajetória de vida, na obra "Conscientização", no capítulo intitulado "O Homem e sua experiência - Paulo Freire por 
BRANDÃO, C. R.; FAGUNDES, M. C. V. Cultura popular e educação popular: expressões da...

si mesmo", descreve de forma sucinta sua biografia. Desta, destacamos aspectos ligados à infância e à imersão na concretude da vida:

[...] em Jaboatão perdi meu pai. Em Jaboatão experimentei o que é a fome e compreendi a fome dos demais. Em Jaboatão, criança ainda, converti-me em homem graças à dor e ao sofrimento que não me submergiam nas sombras da desesperação. Em Jaboatão joguei bola com os meninos do povo. Nadei no rio e tive "minha primeira iluminação": um dia contemplei uma moça despida. Ela me olhou e se pôs a rir... Em Jaboatão, quando tinha dez anos, comecei a pensar que no mundo muitas coisas não andavam bem. Embora fosse criança comecei a perguntar-me o que poderia fazer para ajudar aos homens. (FREIRE, 1980, p. 14).

Sobre sua trajetória escolar e acadêmica, Freire dá ênfase aos estudos sobre Gramática, Literatura, Filosofia e Psicologia da Linguagem, “[...] enquanto se tornava professor do curso ginasial”. Destaca, também, que sua formação teve grande influência de sua primeira esposa, Elza Freire, com quem se casou em 1944, aos 23 anos:

[...] à Elza, professora primária e, depois, diretora de escola, devo muito. [...] Foi a partir do casamento que comecei a me preocupar sistematicamente com problemas educacionais. Estudava mais educação, Filosofia e Sociologia da Educação que Direito, curso que fui um aluno médio. (FREIRE, 1980, p. 15).

Formado em Direito, pela Universidade Federal de Pernambuco, percebeu já no início de sua primeira experiência de atuação profissional que essa não seria sua realização profissional, pois, ao se defrontar com sua primeira causa, a cobrança de uma dívida, abandonou a profissão. A razão da decisão estava, intimamente, ligada com sua postura ética diante da vida e da sociedade. Freire relata que se sentiu feliz com a decisão tomada. A inclinação para ser educador era mais forte. No Serviço Social da Indústria (SESI) retoma seus diálogos com o povo. Como diretor do Departamento de Educação e de Cultura do SESI, em Pernambuco, e depois na Superintendência, de 1946 a 1954, fez suas primeiras experiências que o conduziram, mais tarde, à sistematização daquilo que se tornou conhecido como Método Paulo Freire, que iniciou em 1961. 
Em 1960, Paulo Freire concorria à Cátedra de História e Filosofia da Educação, da Escola de Belas Artes da Universidade do Recife. Sua tese "Educação e Atualidade Brasileira", que, mais tarde, se transformaria em livro, "[...] expunha um pensamento original, ponto de partida para a elaboração de uma obra pedagógica que alcançaria repercussão praticamente mundial". (ROSAS, 2001, p. LXVIII). Porém, Paulo Freire obteve o segundo lugar, fato que, segundo Rosas (2001), teria sido o propulsor de sua imersão na proposta de Cultura Popular, por meio de sua ação no Serviço de Extensão Cultural da Universidade do Recife (SEC) e na vinculação com o Movimento de Cultura Popular, este criado por Miguel Arraes, juntamente com estudantes, o povo e intelectuais pernambucanos.

No início da "década que não acabou", como ficou conhecido o período dos anos de 1960, esboços de novas ideias e propostas de ação social, através da cultura e da educação, junto às classes populares, emergem no Brasil e se difundem pela América Latina. Nos seus primeiros documentos, a ideia de uma nova cultura popular irrompe como uma alternativa pedagógica de trabalho político, que parte da cultura e se realiza por meio da cultura.

Associadas a projetos que vieram a constituir, mais tarde, a educação popular, foram criados os primeiros movimentos de cultura popular em algumas regiões do Brasil. Osmar Fávero (1983) organizou uma obra com diferentes sujeitos desse processo, tornando evidente a ideia de que, apesar de divergentes em alguns pontos essenciais, as iniciativas reunidas nos e como movimentos de cultura popular, dos cinco primeiros anos da década dos anos 1960, partem de uma releitura crítica da política, da sociedade e da cultura brasileira. Esses movimentos repensam de forma radical o que deveria caracterizar as interações entre aqueles que escrevem teoria e estabelecem propostas de ação cultural inclusive no campo da educação - e os sujeitos populares criadores de cultura.

Os movimentos de cultura popular partem do princípio de que o trabalho de transformar e significar o mundo é o mesmo que transforma e significa o homem e a mulher. Como uma prática sempre coletiva e socialmente significativa, o ser humano se realiza através de ações culturalmente tidas como necessárias e motivadas. Assim, a própria sociedade, em que o homem e a mulher se convertem em um ser humano, é parte da/s cultura/s, no sentido mais amplo que se possa atribuir a esta palavra. Também a consciência do homem e da mulher - como aquilo que permite a eles não apenas conhecer, como os animais, mas conhecer-se conhecendo, e que lhe faculta transcender simbolicamente o mundo da natureza de que é parte e sobre o qual age - é uma construção social, que constitui e realiza o trabalho humano de agir sobre o mundo, enquanto age significativamente sobre si mesmo. 
Se por toda a parte existe na sociedade capitalista, desigual e excludente, uma invasão cultural do polo erudito/dominante sobre a cultura popular, um projeto de ruptura social da desigualdade, da injustiça e da marginalização de pessoas e comunidades populares deveria possuir uma dimensão também cultural. Nessa direção, as propostas de cultura popular dos anos 1960 propõem uma radical inversão, em termos do que se pensava como sendo "o processo da cultura". E esta é a ruptura inovadora que repensa o processo da cultura e a prática da educação em seu interior, como uma contribuição revolucionária na questão da participação de intelectuais militantes e "comprometidos com o povo", no bojo do próprio projeto popular de sua libertação.

Uma educação que, usando termos caros a Paulo Freire, vá além de ensinar pessoas a apenas lerem e repetirem palavras, as coensinem a lerem criticamente o seu mundo. Para tornar educandos populares sujeitos críticos e criativos, por meio de uma prática de crescente reflexão conscientizada e conscientizadora, o papel do educador "erudito" e "comprometido" consiste em assessorar homens e mulheres das classes populares na tarefa de ajudar - de dentro para fora e de baixo para cima - a se tornarem capazes de serem os construtores de uma nova cultura popular, a partir de novas práticas coletivas.

Esse caminho de criação de uma polivalente cultura popular que, passo a passo, seria despojada de valores impositivamente dominantes, que refletem a lógica do lugar social hegemônico do mundo e da vida para, finalmente, se constituir livre dos saberes, sentidos, significados e valores dela e de seus enganos. Uma nova cultura, nascida de atos populares de liberação, que espelhe, na prática da liberdade, a realidade da vida social em toda sua transparência.

Sendo um processo de trânsito de uma concepção de cultura e educação popular para outra, Freire (1983) destaca que por ser um processo dialético os valores emergentes vão se estabelecendo, na busca de afirmação no tensionamento com os valores de ontem, que buscam a preservação.

Considerando que na sociedade capitalista há uma produção e uso sistemático das manifestações culturais, a serviço de sua preservação, caberia aos promotores da cultura e educação populares empreender no trabalho ideológico de recriação com o próprio povo, de sua própria cultura. Assim, culturas do povo deveriam ser transformadas em autênticas culturas populares, através de experiências dialógicas de Cultura Popular.

Um dos desafios postos era, ao invés de promover uma invasão cultural, criar situações existenciais para que o homem e a mulher analfabetos pudessem romper com a compreensão mágica sobre a realidade, sentindo-se "[...] capaz de superar a via puramente sensível da captação dos dados da realidade, por uma via crítica". (FREIRE, 1983, p. 113). Freire lembra que outra referência seria a da clareza de que a educação trava uma relação dialética com a cultura 
e que, portanto, não poderia a experiência educativa sobrepor-se à realidade contextual desses sujeitos, sob pena de repetir as falhas da educação alienada.

Ao tomar como referência a cultura como um processo histórico, portanto dialético, é possível afirmar que o homem e a mulher, em relação ativa (conhecimento e ação) com o mundo e com os outros homens e com as outras mulheres, "[...] transformam a natureza e se transformam a si mesmos, construindo um mundo qualitativamente novo de significações, valores e obras humanas e realizando-se como homem/mulher neste mundo humano. (FÁVERO, 1983, p. 16). Nessa lógica, a ação política através de ações culturais, para ser libertadora, deveria partir dos símbolos e dos significados das próprias raízes culturais populares - $\mathrm{a}$ arte popular, os saberes populares, as diferentes tradições populares em todas as suas dimensões, os costumes, etc. -, repensando-as a partir da associação entre a sua experiência de vida e a autônoma interação com/entre os agentes e os recursos do movimento de cultura popular.

Analisando dialeticamente, esse mesmo processo que pode ser libertador, pode ser usado para a dominação. Como mediadora de dominação, a cultura manifesta-se como anti-histórica - quando impede a realização do ser humano na livre comunicação com outro ser humano; anti-social - ao impedir a realização da comunicação como uma tarefa comum para edificação da sociedade como mundo humano; antipessoal - ao trazer em si uma referência ao outro ser humano como objeto de dominação; e antiuniversal - ao separar o todo social em grupos privilegiados e grupos espoliados. (FÁVERO, 1983, p. 19).

A polarização ideológica da cultura contemporânea e seu uso para manutenção da alienação dos sujeitos colocam em pauta o desafio de fazer com que a cultura seja promotora de realização do homem e da mulher como seres de comunicação, possibilitando a abertura das consciências num grau de universalidade crescente. Nessa direção, Fávero (1983, p. 23) afirma que "[...] é popular a cultura que leva o homem e mulher a assumir a sua posição de sujeito da própria criação cultural e de operário consciente do processo histórico em que se acha inserido".

Ao situar o homem e a mulher na condição de criadores e não só de receptores das expressões culturais, Paulo Freire revela a possibilidade de que o movimento de cultura popular seja finalmente reflexivo e não reflexo, completando, assim, a sua missão histórica quando se afirmasse como uma livre, autônoma e aberta cultura nacional. Rompidas as estruturas de domínio de uma classe social sobre as outras, ambas se uniriam em um mesmo sistema aberto de símbolos, de múltiplos saberes e de sensibilidades e significados, regido pela possibilidade de recriação de valores e conhecimentos fundados na conciliação entre pessoas, classes, cultura e consciências. 
Com a intencionalidade de criar um instrumental de cultura popular que pudesse ser usado nas ações populares, o documento de ação popular divulgado em 1963, publicizado por Fávero (1983), lista como possibilidades: alfabetização, núcleos populares, praças de cultura, teatro, artes plásticas, cinema, música, publicações, festas populares, festivais de cultura e todos os outros que se propõem à mobilização popular - meios de conscientização, politização e organização do povo. O documento destaca que a utilização desses instrumentos de cultura popular vincula-se ao contexto e à realidade dos sujeitos envolvidos na ação cultural. A possibilidade de diálogo com o povo, no dinamismo do trabalho de conscientização e politização, impele as entidades e organizações já existentes a recorrerem aos valores do povo. $\mathrm{O}$ autor alerta, ainda, que a preocupação não é de lançar mão desses instrumentos de uma única só vez, mas sempre que melhor respondam aos objetivos propostos e aos movimentos que irão surgindo nas comunicações.

Possivelmente, na alfabetização de adultos, os movimentos de cultura popular tenham conseguido realizar as suas ideias de uma maneira mais contínua e duradoura, durante a efêmera existência da maior parte delas. A partir das experiências de Paulo Freire e sua equipe pioneira no Nordeste, todo um trabalho de alfabetização começava por uma pesquisa conjunta do universo cultural popular. Depois, as próprias aulas eram transformadas em círculos de cultura, onde o trabalho de ensinar-e-aprender ganhava uma inesperada e inovadora dimensão dialogal. No Círculo de Cultura, observava-se a superação do professor pelo coordenador de debates, do aluno pelo participante do grupo, da aula como exposição de conteúdos pelo diálogo, dos "[...] programas por situações existenciais, capazes de, desafiando os grupos, levá-los, pelos debates das mesmas, a posições mais críticas". (FREIRE, 1983, p. 115). Assim, o próprio ensino de leitura de palavras do português começava e continuava por uma reflexão coletiva, a partir da questão teórica da cultura e dos elementos da cultura local de cada grupo de educandos. Não se tratava de aprender apenas a ler e escrever em uma língua, como nos programas tradicionais de alfabetização de adultos, mas de aprender a “ $[\ldots .$.$] ler o seu próprio mundo através de sua própria$ cultura [...], a cultura como acrescentamento que o homem faz ao mundo que ele não fez. A cultura como resultado de seu trabalho. Do seu esforço criador e recriador". (FREIRE, 2013, p. 116). Daí, a importância de comunicar-se com o outro como um sujeito consciente no mundo e com o mundo e não objeto.

$\mathrm{O}$ que as ideias de Paulo Freire e as práticas - breves e fecundas - dos movimentos de cultura popular procuram estabelecer em seu tempo e nos deixam como herança são esboçadas por Brandão (2014) e aqui resumidas:

a) Têm como ponto de partida a busca de uma interação equitativa entre diversos campos de pensamento, criação e ação social, através dos saberes das 
ciências, cinema, teatro, literatura, música, artes plásticas, educação, vivida como arte e prática, compreendidas como diferentes domínios humanos de criação de novas ideias, com uma convergente vocação político-transformadora. Assim, seria através da partilha de todas e de cada uma dessas vocações, no interior de projetos de "criação do novo" e de "transformação através da inovação" que uma nova cultura deveria ser, paulatinamente, criada;

b) Buscam uma convergência de/entre culturas. Em termos concretos, elas buscam estabelecer novas alianças entre pessoas e grupos de vida e vocação acadêmica ou artística (eruditos, acadêmicos), com autores/atores populares individuais ou coletivos. Este complexo processo de criação de "estradas de mão dupla" na criação e gestão de estilos de arte e sistemas de educação tomam um rumo bem diverso do que se praticava até então. Isto porque não eram pensados e praticados como um outro "serviço cultural" ou educacional complementar ao povo. Não se trata de estender ao "oprimido" os padrões de gosto e as ideologias de moda do "opressor", mas de partir de um diálogo tão igualitário quanto possível, que termine por criar meios de autotransformação de pessoas, grupos sociais e movimentos populares em construtores e gestores de sua autonomia e também em condutores de um processo de ruptura da hegemonia "burguesa" e de transformação radical da sociedade;

c) Elas colocam a cultura e a política no centro do próprio acontecer da educação. É nesta direção que insistimos em lembrar que para Paulo Freire e seus companheiros a educação é pensada como um campo da cultura e a cultura como algo cuja dimensão de realização tem a ver com a gestão de formas de poder simbólico, que tanto podem reiterar e reproduzir uma conjuntura social de desigualdade e de opressão, quanto podem configurar a dimensão simbólica de teor político da construção de uma nova ordem social de libertação.

Não se trata de criar contextos de soluções pessoais para conflitos sociais, mas da busca solidária de soluções sociais para problemas pessoais. Este seria o momento de uma inversão de uma educação para o povo, em direção a uma educação que o povo cria ao transitar de sujeito econômico a sujeito político e ao se reapropriar de um modelo de educação para fazê-la ser $a$ educação do seu projeto histórico. Não esquecer que "sujeito político" tem, em Paulo Freire, a conotação do agente consciente-e-crítico e, portanto, pessoa criativamente ativa e corresponsável e participante pela gestão e transformação de sua polis, o seu lugar de vida e destino;

d) Elas procuram estabelecer e difundir uma experiência de educação que anos mais tarde receberá o qualificador "popular". Desde os primeiros escritos da "equipe pioneira", não estarão restritas a um método de trabalho, como aquele criado para a alfabetização de adultos, mas como um "sistema de educação", que tem em seu andar térreo a alfabetização e na cobertura a proposta de criação 
de uma universidade popular. Isto acontece vários anos antes da reinvenção de propostas de universidades alternativas, livres ou populares que surgem por todo o mundo.

\section{O sistema Paulo Freire de educação: da alfabetização à universidade popular}

Depois de uma trajetória brevíssima como advogado e de oito anos de trabalho no Serviço Social da Indústria, em Pernambuco, Paulo Freire experimenta as inovações de dinâmica de grupos e de novas práticas dialógicas de ensino-aprendizagem. Logo nos primeiros tempos de sua carreira, ele participa da criação do Serviço de Extensão Cultural da Universidade do Recife e, sendo seu primeiro diretor, inicia uma revolução cultural na universidade dando início a um grande e abrangente processo de comunicação.

Para Maciel (1983), que era um dos integrantes da equipe de trabalho do Serviço de Extensão Cultural (SEC), dirigido por Freire, a extensão cultural tinha a dimensão da democratização da cultura. "Extensão é uma dimensão da pré-revolução brasileira, desde que ela também - e não só o homem, na expressão feliz de Gabriel Marcel - é situada e datada". (MACIEL, 1983, p. 127). Prossegue o autor afirmando que a universidade brasileira, daqueles anos 1960, não poderia permanecer voltada sobre si mesma e para o passado, indiferente aos problemas cruciais que afligiam o povo que ela deveria servir. Essa é uma afirmação que nos parece ser extremamente válida para a universidade de nosso século XXI, como possibilidade de repensar e sulear os caminhos para a democratização da universidade, realizando a transição de uma cultura e educação, pautada na tradição de formação de elites para as elites, para se colocar junto com a população e pensar processos democráticos de cultura e educação.

A Universidade Federal de Recife, por meio do SEC, revisitou seu projeto político e alterou parte de sua ação no momento em que colocou em discussão o papel da universidade. Nas palavras do então Reitor João Alfredo Gonçalves da Costa Lima, em fevereiro do ano de 1962, “[...] a ação da Universidade não se deve sobrepor ao processo de desenvolvimento, mas antes nele se inserir, proporcionando constante integração de professores e alunos na comunidade. (MACIEL, 1983, p. 128).

A avaliação levava em consideração a realidade concreta vivida pelo Nordeste naqueles tempos e o entendimento decorrente de que não teria sentido uma universidade alienada ao processo de desenvolvimento, o que lhe coloca- 
ria em uma situação de marginalização de seu tempo. Para abri-la e tirá-la de seu isolamento, inserindo-a no trânsito brasileiro, caberia à extensão cultural assentar suas preocupações sobre os problemas mais urgentes daqueles dias. Isso significaria assumir uma proposta que colocaria em choque os interesses da pequena elite, presente na universidade, com a grande maioria da população que, talvez nesse contexto histórico, jamais pensasse em dialogar com a universidade. O contraditório dessa aproximação seria o fato de que os excluídos da universidade dariam legitimidade ao modo de ser, estar e fazer da universidade, na condição de instituição pública de educação e cultura.

Próximo a essa ideia de resgate de legitimidade e de hegemonia da universidade, Boaventura de Sousa Santos, em sua obra "Pela mão de Alice", publicada no ano de 2000, portanto 40 anos mais tarde, defende que uma das formas da universidade recuperar e quebrar seu isolamento ancestral seria mudar no essencial, ou seja, democratizar-se na ação e concepção da construção de saberes. Como um dos caminhos, preconiza a ruptura epistemológica assentada na reinvenção da extensão. Embora não cite Freire, Santos utiliza fundamentos idênticos aos seus.

Retornando aos anos 1960, no Serviço de Extensão Cultural da Universidade do Recife, Paulo Freire e sua equipe criavam o sistema de educação em que uma universidade popular estaria presente. Recuperar essa proposta dos anos 1960, por meio de registros de Freire e de seus companheiros do SEC, faz-se fundamental, dada a dimensão de emancipação humana que abriga, ensejando o fortalecimento de ações na direção da transição do modelo dominante liberal para uma educação libertadora.

Maciel (1983, p. 129) relembra que as discussões colocavam como ponto de partida para a democratização da cultura o processo de alfabetização, desenvolvido pela universidade, por meio do Serviço de Extensão Cultural. O autor afirma, ainda, que a proposta de universidade popular principia pela própria universidade, por meio da extensão cultural, cabendo a ela, "[...] através da extensão e empenhada em democratizar a cultura, voltar-se inicialmente, com todas as suas forças contra o analfabetismo". (MACIEL, 1983, p. 129). Levar a universidade a agir com o povo, por meio de cursos de extensão nos níveis secundário, médio e superior, foi o ponto de partida do SEC.

A alfabetização, ou o método de alfabetização, tornava-se um elo entre as diversas etapas e transformava-se em um sistema de educação integral e fundamental, “[...] desembocando com toda a tranquilidade numa autêntica e coerente Universidade Popular", afirma Maciel (1983, p. 129).

Essa proposta do Sistema Paulo Freire de Educação, do começo dos anos de 1960, é pouco lembrada, talvez porque nunca tenha sido realizada para além das experiências com o Método Paulo Freire, mesmo tendo sido uma ferramenta 
BRANDÃO, C. R.; FAGUNDES, M. C. V. Cultura popular e educação popular: expressões da...

da práxis da revolução brasileira. A proposta desdobrava-se em seis etapas, conforme consta na obra de Maciel (1983):

Primeira etapa do Sistema - alfabetização infantil.

Segunda etapa do Sistema - alfabetização de adultos. Consta, em largos traços, de um método de alfabetização rápida ( 28 a 40 horas), sem cartilha, sem o professor tradicional, fazendo utilização ampla de ajudas de audiovisuais (projeção fixa, atualmente) e da motivação a partir de situações existenciais dos grupos a alfabetizar, conscientizando pelo diálogo franco e informal. Parte, para isso, do levantamento do universo vocabular dos alfabetizandos, de onde são retiradas as chamadas "palavras geradoras" para alfabetização.

Terceira etapa $-[\ldots]$ é o ciclo primário rápido (de 8 a 10 meses). Nesta etapa, uma vez alfabetizado, o adulto começará a ler pequenas antologias de textos reduzidos a universos vocabulares limitados e a estudar em "pequenos manuais de capacitação cívica", nos quais encontramos noções básicas de legislação do trabalho, geografia econômica, economia, sindicalismo, etc. Assuntos técnicos ligados às profissões e ocupações dos recém-alfabetizados serão incluídos nestes manuais, bem como noções de arte popular e folclórica (mamulengos, dramatizações, poesia nordestina popular). Será tentada a inclusão aí de reduções a vocabulários mínimos das chamadas Ciências do Homem. Os adultos, nesta etapa, serão encorajados a escrever pequenos "artigos" para seu próprio "jornal" (com o qual estão acostumados desde a segunda etapa) e para pequenos "livros" escritos em conjunto intercambiados pelos diversos "círculos de cultura" do Estado, da Região e, mais tarde, do Brasil inteiro. Formar-se-ão, também bibliotecas populares etc.

A quarta etapa do Sistema, juntamente com a anterior, marca o início da experiência de universidade popular propriamente dita, entre nós. $\underline{\text { Será a }}$ extensão cultural, em níveis popular, secundário, pré-universitário e universitário. Esta é a fase de trabalho atual do SEC, mas atingindo clientelas de áreas urbanas recifenses, de nível secundário em diante.

Para instalação desta etapa e das seguintes - que constituem a Universidade Popular - serão aproveitados os "círculos de cultura" nos quais se fez a alfabetização e, aqui em Pernambuco, as Associações de Bairro e os Sindicatos Rurais, estabelecendo-se assim uma rede de pequenos "institutos de estudos brasileiros" (IPEBs) ligados à Universidade do Recife, que funcionarão como verdadeira universidade volante. Em Pernambuco, o SEC, o MCP (Movimento de Cultura Popular), a Promoção 
Social, o MEB (Movimento de Educação de Base), a AP (Ação Popular) e a SUDENE (Setor de Reformulação Agrária) mobilizam-se no sentido de instalar estas etapas anteriores do Sistema.

A quinta etapa do Sistema - já esboçada com suficiente profundidade para permitir a presente extrapolação - desembocará tranquila e coerentemente no Instituto de Ciências do Homem, da Universidade do Recife, com o qual o SEC trabalhará em íntima colaboração.

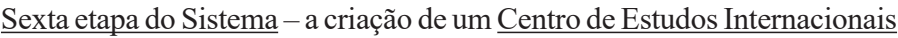
(CEI), da Universidade do Recife. Este órgão havia já sido criado e previa uma "intensa transação com os países subdesenvolvidos num esforço de integração do chamado Terceiro Mundo, conforme é o pensamento do Prof. Vamireh Chacon”. (MACIEL, 1983, p. 130-131).

Como visto, o Sistema Paulo Freire de Educação tinha como desafio atuar em uma sociedade em trânsito, que marchava de forma acelerada à procura de novos temas e de novas tarefas. (FREIRE, 2003). A passagem de uma época para outra colocava, para a educação e para o educador e educadora, a necessidade de discutir toda e qualquer temática na relação direta com a cultura instituída e instituinte na relação dialética parte e todo. Essa leitura de mundo buscava a desalienação cultural, por meio da criticização da sociedade fechada e colocava como extrema preocupação o caminho para a construção de uma sociedade aberta, com o implícito receio de transformar-se em uma nova sociedade de massas, em que descriticizado se tornariam o homem e a mulher acomodados e domesticados.

\section{Alinhavando o possível}

As ações culturais populares, decorrentes dos movimentos de cultura popular, trabalhavam baseadas na realidade concreta de seus sujeitos, reconhecendo suas próprias raízes culturais populares, em suas distintas manifestações, como a arte popular, os saberes populares, a música, as festas populares, as diferentes tradições, os costumes, elementos de significação e de produção da própria existência, expressões que passaram a compor a ação popular e a educação popular.

O sistema Paulo Freire de educação recolocava a possibilidade de organizar uma outra proposta de educação democrática, para além da lógica dominante, em que a cultura popular passava a assumir o papel preponderante como elo de 
ligação e reconhecimento identitários e de libertação de seus sujeitos, como seres sociais e políticos, nas infindáveis possibilidades de diálogos entre o próprio grupo, com diferentes grupos e distintos lugares, reconhecendo a existência de conhecimentos e culturas.

O sistema freireano de educação baseava-se em uma educação para a decisão, que fosse dialogal e ativa, voltada para a responsabilidade social e política, ancorada em uma profunda interpretação dos problemas, assentada em um trabalho pedagógico crítico, apoiado em condições históricas propícias. (FREIRE, 2003). Esse processo educativo não deveria descuidar do encorajamento do homem e da mulher para se inserirem e discutirem a problemática da sociedade de seu tempo e, conscientes deles, pudessem, por meio do diálogo constante, superar as prescrições alheias a si, criando, assim, “[...] uma certa rebeldia, no sentido mais humano da expressão, que o identificasse com métodos e processos científicos". (FREIRE, 2003, p. 98). Essa proposta educativa fundava-se na construção da consciência crítica, construída na ação e reflexão das mulheres e homens com e no seu tempo.

O respeito e o reconhecimento da existência de distintos conhecimentos e culturas, componentes da ação cultural, expressava muito mais do que uma mera tática de aproximação com as massas populares, mas o entendimento de que seria esse o caminho para a construção de um processo de revolução cultural e de libertação.

A proposta do sistema de educação freireano assentou-se nos princípios da extensão cultural desenvolvida, naquele momento, por meio da Universidade de Recife. Um movimento que, através do diálogo e assentado na realidade histórica desse tempo e espaço, propunha aos homens e às mulheres refletirem sobre sua ontológica vocação de ser sujeito. Diálogo entendido por Freire (2002) como possibilidade da problematização, em que educador-educando e educando-educador desenvolvem uma postura crítica e a percepção de um saber que se encontra atrelado ao mundo e a homens e mulheres, tornando possível explicar o mundo e sua transformação.

A proposta buscava não a criação de outra universidade, mas a transformação radical da universidade existente, dando-lhe um outro papel político em que o novo conteúdo, como ponto de partida, seria a cultura, definida como “[...] acrescentamento que o homem faz ao mundo que não fez. A cultura como resultado do trabalho, do esforço criador e recriador dos seres humanos. A cultura como aquisição sistemática da experiência humana". (FREIRE, 2003, p. 117). Intrinsicamente ligado a esse conceito de cultura, decorreria o sentido transcendental das relações; a democratização da cultura; o homem/mulher com o mundo e o seu papel de sujeito e não de mero e permanente objeto. 
Assim, a proposta epistemológica que suleava a construção de um sistema de educação privilegiava a formação do sujeito na sua dimensão humana de ser social. Uma proposta que tinha a universidade como ponto de partida, porém a extrapolava no momento seguinte, já na primeira etapa, e se expandia ocupando os círculos de cultura, centros de cultura e outros espaços e movimentos populares, alcançando, por fim, o diálogo com o chamado Terceiro Mundo numa perspectiva de integração e de libertação.

Portanto, mais do que lembrar essa experiência vivida no Brasil, cabe-nos reinventá-la, tomando-a inspiração para o enfrentamento destes turbulentos dias de 2016, em que a direita liberal avança na direção da supressão das conquistas sociais da classe trabalhadora, violenta com as muitas culturas e os sujeitos que as produzem, ao insistir em padronizar um único currículo nacional. Assim sendo, parece-nos ser uma oportunidade histórica para, a partir desta realidade também histórica, recuperarmos nossa dimensão política de sujeitos construtores de cultura e de história, como possibilidade de enfrentamento de tal situação-limite.

\section{REFERÊNCIAS}

BRANDÃO, C. R. Paulo Freire: a educação, a cultura e a universidade. Memória de uma história de cinquenta anos atrás. Eja em debate, Florianópolis, ano 3, n. 4, jul. 2014.

FÁVERO, O. (Org.). Cultura popular, educação popular: memória dos anos 60 . Rio de Janeiro: Graal, 1983.

FÁVERO, O. Uma pedagogia da participação popular: análise da prática educativa do MEB - Movimento de Educação de Base (1961/1966). Campinas: Autores Associados, 2006.

FREIRE, P. Conscientização: teoria e prática da libertação. Uma introdução ao pensamento de Paulo Freire. São Paulo: Editora Moraes, 1980.

FREIRE, P. Conscientização e alfabetização: uma nova visão do processo. In: FÁVERO, O. (Org.). Cultura popular, educação popular: memória dos anos 60. Rio de Janeiro: Graal, 1983.

FREIRE, P. Extensão ou comunicação? Rio de Janeiro: Paz e Terra, 2002.

FREIRE, P. Educação como prática da liberdade. Rio de Janeiro: Paz e Terra, 2003.

GULLAR, F. Cultura popular. In: FÁVERO, O. (Org.). Cultura popular, educação popular: memória dos anos 60. Rio de Janeiro: Graal, 1983. 
BRANDÃO, C. R.; FAGUNDES, M. C. V. Cultura popular e educação popular: expressões da...

MACIEL, J. Fundamentação teórica do Sistema Paulo Freire de Educação. In: FÁVERO, O. (Org.). Cultura popular, educação popular: memória dos anos 60. Rio de Janeiro: Graal, 1983.

PRADO JUNIOR, C. A Revolução Brasileira. São Paulo: Brasiliense, 1966.

ROSAS, P. Recife - Cultura e participação (1950-64). In: FREIRE, P. Educação e atualidade brasileira. São Paulo: Cortez Editora, 2001.

SOUSA SANTOS, B. Pela mão de Alice: o social e o político na pós-modernidade. 7. ed. São Paulo: Cortez, 2000.

Texto recebido em 16 de junho de 2016. Texto aprovado em 16 de junho de 2016. 